\title{
A PÁTRIA EDUCADORA E O ABANDONO DA EDUCAÇ̃̃O SUPERIOR: A PREDOMINÂNCIA DOS INTERESSES DOS EMPRESÁRIOS DA EDUCAÇÃO
}

\author{
Alisson Slider do Nascimento de Paula ${ }^{1}$ \\ Kátia Regina Rodrigues Lima ${ }^{2}$ \\ Emmanoel Lima Ferreira ${ }^{3}$ \\ Frederico Jorge Ferreira Costa ${ }^{4}$
}

\section{RESUMO}

Este estudo busca desvelar o conteúdo subjacente da política educacional expressa nos governos Lula da Silva e Dilma Rousseff, tendo em vista o lema governamental: Pátria Educadora e sua relação com a educação superior, em especial. Para trato metodológico, realizou-se um estudo teórico e documental, delimitando os documentos: Plano Nacional de Educação 2014-2024, e o documento Pátria Educadora. O método de análise adotado foi o materialismo histórico e dialético por se propor em apreender o objeto como síntese de múltiplas determinações, assim, concebendo um fenômeno para além de sua expressão imediata e isolada, partindo do mais geral para o mais específico. Constatou-se que as diretrizes da política educacional brasileira são, em grande medida, engendradas pelo setor empresarial, além de dar uma maior relevância para a educação básica, deixando a educação superior a cargo da iniciativa privada, efetivando, deste modo, o processo de mercadorização deste nível de ensino por ser considerado altamente rentável para extração de lucros para o capital.

Palavras-chave: Educação Superior; Pátria Educadora; Empresários da Educação; PNE (2014-2024);

\section{THE HOMELAND EDUCATOR AND ABANDONMENT OF HIGHER EDUCATION: THE PREDOMINANCE OF THE INTERESTS OF THE EDUCATION BUSINESS}

\begin{abstract}
This study aimed to reveal the underlying content of educational policy expressed in Lula da Silva and Dilma Rousseff, in view of the government's motto: Educator country and its relationship with higher education in particular. For methodological treatment, there was a theoretical and documentary study, delimiting documents: National Education Plan 20142024, and the document Homeland Educator. The adopted method of analysis was historical materialism dialectic by proposing to grasp the object as a synthesis of multiple determinations, thus conceiving a phenomenon beyond its immediate and isolated expression, starting from the most general to the most specific. It was found that the guidelines of the Brazilian educational policy are largely engendered by the business sector, in addition to giving greater importance to basic education, leaving higher education in charge of the private sector, effecting thus the process of commodification of this level to be considered highly profitable to extract profits for capital.

Keywords: Higher Education; Educating country; Education entrepreneurs; PNE (20142024);
\end{abstract}




\section{Introdução}

$\mathrm{O}$ presente trabalho busca, dentro de suas limitações, compreender a processualidade em que se realiza no bojo das contradições do capital mundializado, o interesse da proposta Pátria Educadora enquanto diretriz para a educação brasileira, e o lugar no qual está localizado a educação superior nesse contexto. Compreendendo os fenômenos que decorreram da mundialização capitalista e seus decorrentes efeitos sobre todas as esferas da vida humana, inclusive, a educação à qual é concebida como setor estratégico no que diz respeito à irradiação ideológica no tocante a dominação hegemônica, bem como do empresariamento educacional, em especial, o ensino superior. Portanto, partimos do universal - processo da expansão capitalista em escala global - para o particular - a educação superior brasileira sob as condicionalidades postas do capital no limite de sua processualidade na particularidade capitalista dependente brasileira, assim como as reverberações na proposta Pátria Educadora -, para que assim, possamos desenvolver o objetivo do referido trabalho.

Cientes da dimensão do desafio proposto, não caímos no equívoco de tomar qualquer conclusão prévia, pois os fatos podem vir a trilhar em caminhos opostos ao que foi inferido dentro de nossas análises. A rigor, compreendemos que sob o jugo da acumulação flexível, os interesses mercantis ganham ênfase nas tentativas de extração lucrativa, portanto, até setores como educação, que outrora representava um direito social, são incorporados por serem compreendidos como nichos mercantilistas necessários para o capital.

Nesse sentido, como recurso metodológico articulado na pesquisa, nos amparamos em um estudo documental e bibliográfico, assim possibilitando aprofundar os aspectos constitutivos do problema em questão. Concernente o estudo bibliográfico, nos retemos as análises de intelectuais que tratam do objeto educação superior, como (SGUISSARDI, 2008; SGUISSARDI; SILVA JÚNIOR, 2009; SILVA JÚNIOR; ANELLI JÚNIOR; MANCEBO, 2014; RODRIGUES, 2007; LIMA, 2015; 2012; DE PAULA, 2015); no que tange o instrumental utilizado para análise documental, tratou-se dos indicativos de Evangelista (apud, NISHIMURA, 2014, p.49), nos quais denotam: "localizar, selecionar, ler, reler, sistematizar e analisar as evidências contidas nos documentos, relacionando com o aporte teórico organizado". Assim, os documentos que chamaram atenção se trataram: i) Pátria Educadora: a qualificação do ensino básico como obra de construção nacional; ii) Plano Nacional de Educação (PNE - 2014-2024). O método de análise adotado está calcado na perspectiva dialética marxiana, na qual consiste em considerar a dinâmica dos fenômenos concretos em um contexto historicamente determinado, deste modo, compreendendo a totalidade como síntese de múltiplas determinações (MARX, 2013).

Com efeito, parece-nos que a educação superior almejada pela lógica da Pátria Educadora, no cenário da política global do capital, incorpora elementos que alçam sua função para além da produção do conhecimento, isto é, além de deter uma vigorosa disseminação de dominação ideológica, também, possibilita extração de mais-valor a partir de sua operacionalidade no bojo das relações concretas desenvolvidas na particularidade capitalista dependente brasileira, o que atende, de antemão, os interesses dos setores empresariais da educação. Sendo assim, partimos da raiz do problema, pois, doravante compreensão da realidade enquanto um complexo de complexos, não se pode identificar a educação superior apenas como um problema isolado, todavia, integrante de um contexto com interesses em escala mundial. 


\section{O modelo de educação para a periferia capitalista}

Partimos em nossa análise, nessa seção, doravante, compreensão que a política educacional não pode ser compreendida exclusivamente em âmbito nacional. A partir da conjuntura do globo, em que se efetivou a mundialização do capital, os elementos que constituem o patrimônio social de uma nação devem ser analisados em contexto global, logo, compreende-se a relação interdependente que envolve os países centro para a periferia capitalista hodierna.

Nos debates que envolveram a temática referente a políticas públicas de educação nas últimas décadas, localiza-se referências à perspectiva global da educação. Para Amaral (2010), em linhas gerais, faz-se alusão além da globalização, à economia do saber, à internacionalização, entre outras. $\mathrm{O}$ autor complementa que em diversas correntes teóricas têm-se adotado tais perspectivas, "nas ciências sociais, adota-se uma perspectiva global como, por exemplo, na teoria da cultura mundial [...] na teoria do sistema-mundo [...] e na teoria dos sistemas/sociedade mundial" (AMARAL, 2010, p. 41). A educação é tematizada em escala global, os documentos dos organismos internacionais ${ }^{5}$ trazem essa abordagem acerca da política educacional na Organização das Nações Unidas para a Educação, a Ciência e a Cultura (UNESCO), Organização para Cooperação Econômica e Desenvolvimento (OCDE), Banco Mundial (BM) etc. Constata-se que nos últimos anos o modus operandi dos organismos internacionais modificaram-se de modo qualitativo. Dessa forma, diversos sistemas educacionais pelo globo sofreram condicionamentos dos programas empreendidos por estes organismos. Esclarecemos que, levando em conta o hodierno nível de organização internacional, em especial no que diz respeito às políticas educacionais, a análise requer um contexto global para que possa compreender a processualidade em âmbito nacional, assim não correremos o risco de crer em meras expressões fenomênicas no sistema educacional brasileiro, peculiarmente no ensino superior.

No início as políticas educacionais eram integrantes da política social de diversos países, colocada sob tutela do governo nacional - o que pode ser expressado como soberania nacional de educação. Este contexto implica realçar que os organismos internacionais não possuíam qualquer tipo de predomínio na educação, ainda que desde a organização dos Estados-nações existisse uma relevante conexão destes com círculos políticos internacionais.

[...] na literatura em educação comparada, pode-se observar um forte interesse no exterior. Há uma vasta literatura sobre educadores que viajaram por vários países explicitamente em busca de informações sobre educação durante o século XIX: Victor Cousin na França, Horace Mann e Henry Barnard nos EUA, Mathew Arnold na Inglaterra e Domingo Sarmiento na Argentina. A partir do século XX, o Brasil também tem uma história intensa de cooperação internacional em educação (AMARAL, 2010, p 45).

A relação acerca da soberania que envolve o sistema educacional e o Estado-nação tem sido questionado desde a década de 1990. Essa problematização se deu, em grande medida, em função dos fenômenos acerca da mundialização do capital, o que engendrou um determinado nível de desnacionalização nos sistemas de ensino nacionais. Em verdade, desde o II pós-guerra, a atuação dos organismos internacionais na área educacional determinou-se como atividade contínua. No início, estes organismos atuavam como agentes intergovernamentais para reconstruir a Europa em virtude da II grande guerra, 
buscando estimular a compreensão internacional por intermédio da cultura e principalmente da educação.

Exposto isso, ressaltamos que na presente seção, daremos ênfase na atuação do Banco Mundial (BM) - não deixaremos de mencionar outros organismos internacionais, contudo o BM possui uma atuação mais ativa no que concerne às orientações para a política educacional na periferia do capitalismo -, para isso faz-se necessário explorar a essência deste braço do capital financeiro. Portanto,

[...] o Grupo Banco Mundial, em verdade, constitui-se em um organismo multilateral de crédito, integrado por sete instituições: Banco Internacional para Reconstrução e Desenvolvimento (BIRD) e Associação Internacional de Desenvolvimento (AID), que formam o que se conhece efetivamente por Banco Mundial; e a Sociedade Financeira Internacional (SFI), a Agência Multilateral de Garantia de Investimentos (MIGA), o Centro Internacional para Conciliação de Divergências em Investimentos (CICDI), o Instituto do Banco Mundial (IBM) e o Painel de Inspeção (BASTOS; ROCHA, 2015, p. Única).

Destarte, foi por meio da gestão de McNamara (1968-1981) que o BM incorporou a bandeira do combate à pobreza, assim realizando os primeiros empréstimos direcionados para a educação, originando a um colossal reordenamento organizacional, bem como estratégico, no que diz respeito a financiar projetos voltados para áreas sociais nos países subdesenvolvidos, sobretudo a América Latina e a África, territórios nos quais os empréstimos eram canalizados para o âmbito educacional. A estratégia do BM calcada na teoria do capital humano para a periferia compreendia que investimentos "em 'capital humano' deflagrariam um processo de círculo virtuoso naquelas economias, que faria que aqueles países experimentassem prosperidade econômica e social, tirando suas vastas populações de uma situação secular de penúria e miséria" (BASTOS; ROCHA, 2015, p. Única).

Com a crise da dívida eclodindo na década de 1980, à qual abalou grande parte da periferia capitalista, o BM passa a assumir a condução das políticas de educação dos países endividados, sistematizando seu controle a partir de documentos. Com isso, passa-se a direcionar prioridade para a educação básica, logo, na concepção do BM se trata de um nível de ensino mais rentável e barato, decorrendo, assim, na efetivação de meios para que fosse factível a captação de fundos externos ao Estado, o que implica ao autofinanciamento do ensino médio, em especial o ensino superior.

Conforme os princípios basilares do BM, a educação se trata de um investimento que consequentemente, em longo prazo, resultará em efeitos qualitativos para o sistema econômico de uma nação, contudo, em função da carência destes recursos, é necessário ser classificado como primaz os setores subalternos para que possam maximizar os retornos dos recursos investidos. "A preocupação com a pobreza estava em suas estratégias, mas agregada à racionalidade dos custos financeiros, para alcançar os objetivos da educação primária (primeiro ciclo).” (SILVA apud BASTOS; ROCHA, 2015, p. Única).

Portanto, a reforma dos sistemas educacionais das nações subdesenvolvidas, dizem respeito, necessariamente, à educação básica das camadas subalternas - além dos mecanismos avaliativos que possam medir resultados para o controle de gasto -, consoante às orientações do $\mathrm{BM}$, decorre, deste modo, no abandono da educação superior por parte do poder público estatal. É lícito ressaltar a prioridade dada ao modelo de ensino técnico e vocacional em que são priorizadas as competências necessárias para o mundo do trabalho, 
ao passo que a formação humana baseada na reflexão crítica e apreensão do conhecimento historicamente produzido pela sociedade fica em segundo plano.

Segundo De Paula (2015), a educação superior ganha ênfase nos documentos do BM doravante, década de 1990, propiciando:

[...] quatro documentos [...] Seguindo a ordem cronológica de suas publicações: (i) 1994 - Educação Superior: as lições da experiência; (ii) 2000 - Educação Superior nos países em desenvolvimento: perigo e promessa; (iii) 2002 - Construindo sociedades do conhecimento: novos desafios para a educação terciária; e (iv) Educação Permanente na economia global do conhecimento: desafios para os países em desenvolvimento. (DE PAULA, 2015, p. 63).

Desde a publicação do primeiro documento referente ao ensino superior pelo BM em 1994, é visível a intenção de erradicar o modelo neo-humboldtiano de universidade. Assim, o BM orienta para a periferia capitalista um modelo de universidade operacional (CHAUÍ, 2003), a-histórica, a-crítica, em que a produção do conhecimento esteja calcada na base utilitarista em um teor pragmático, para este organismo internacional, esse modelo estaria compatível para um país capitalista dependente, assim, seria engendrado um padrão dependente de universidade (FERNANDES, 1975).

Contudo, para efetivar tais intentos para a educação da periferia capitalista, os mecanismos ganharam força material com o processo da reforma do aparelho do Estado. Vale ressaltar que esteve em consonância com os desígnios do BM, basta verificar o documento publicado em 1997 - "Relatório sobre o Desenvolvimento Mundial" -, no qual trata, peculiarmente, do reordenamento do Estado dos países da periferia capitalista. Este documento engendra uma concepção de Estado mínimo, contudo aberto ao mercado, ensejando este último à função de gerir a processualidade das relações sociais, o que corrobora uma noção do que seria um mercado próximo do povo, contudo, um Estado ativo para as transformações do mundo mercantil hodierno (BANCO MUNDIA, 1997).

O processo de reforma do Estado brasileiro efetivou-se durante a década de 1990 e início dos anos 2000, ensejando, deste modo, conforme Lima (2011, p. 88) "um intenso processo de privatização dos serviços públicos, incluindo a educação e, especialmente, a educação superior". Estes mecanismos estiveram calcados nas concepções neoliberais, localizando uma essência privatista que orienta a atividade estatal que diz respeito à "oferta dos serviços públicos de ensino superior, compreendidos, desde então, como "não exclusivos' do Estado".

Deste modo, lançando olhos para a política de educação superior a partir dos governos Lula da Silva e Dilma Rousseff ${ }^{6}$, identificamos a implementação de uma miríade de políticas às quais possibilitaram a efetivação da reforma da educação superior brasileira $^{7}$. Estas políticas concernem a um aparato jurídico-político que tornara exequível vincular os anseios dos empresários da educação com o ensino superior (RODRIGUES, 2007). Em síntese, ressaltamos que não analisaremos cada política em sua singularidade, pois ultrapassa os limites da presente pesquisa, contudo, é necessário expor de modo ilustrativo algumas destas políticas, para tanto, recorreremos a uma exposição sucinta e bastante clara de Lima (2009):

[...] (i) o Sistema Nacional de Avaliação do Ensino Superior (Sinaes) Lei $\mathrm{n}^{\circ}$ 10.861/2004; (ii) o Decreto $\mathrm{n}^{\circ} 5.205 / 2004$, que regulamenta as parcerias entre as universidades federais e as fundações de direito privado, viabilizando a captação de recursos privados para financiar as 
atividades acadêmicas; (iii) a Lei de Inovação Tecnológica $\left(\mathrm{n}^{\mathrm{o}}\right.$ 10.973/2004) que trata do estabelecimento de parcerias entre universidades públicas e empresas; (iv) o Projeto de Lei $n^{\circ}$ 3.627/2004 que institui o Sistema Especial de Reserva de Vagas; (v) os projetos de lei e decretos que tratam da reformulação da educação profissional e tecnológica; (vi) o Projeto de Parceria Público-Privada (PPP) (Lei ${ }^{\circ}$ 11.079/2004) que abrange um vasto conjunto de atividades governamentais, (vii) o Programa Universidade para Todos (ProUni) Lei no 11.096/2005 - que trata de "generosa" ampliação de isenção fiscal para as instituições privadas de ensino superior; (viii) o Projeto de Lei 7.200/06 que trata da Reforma da Educação Superior e se encontra no Congresso Nacional; (ix) a política de educação superior a distância, especialmente a partir da criação da Universidade Aberta do Brasil e, mais recentemente (2007), (x) o Programa de Apoio a Planos de Reestruturação e Expansão das Universidades Federais/REUNI e o Banco de Professor-Equivalente. (LIMA, 2009, p. 2).

Realçamos que o Programa de Apoio a Planos de Reestruturação e Expansão das Universidades Federais (REUNI), instituído pelo Decreto $n^{\circ}$ 6.096/07 (BRASIL, 2007a), se trata de uma das medidas do Plano de Desenvolvimento da Educação (PDE) (BRASIL, 2007b), que por sua vez, objetiva materializar as metas do Movimento Todos Pela Educação (TPE) ${ }^{8}$. Deste modo, constatamos que o plano de ação fundamental para o setor educacional no governo Lula da Silva, se tratou do PDE, que podemos destacar que sua essência e muitas de suas metas são assumidas pelo novo Plano Nacional de Educação (PNE 2014-2024) instituído pela Lei $\mathrm{n}^{\circ}$ 13.005/14 (BRASIL, 2014). Sendo assim, no governo Dilma Rousseff foi dada para a educação a mesma atenção à qual foi dada no governo precedente, ou seja, voltada à atender os interesses dos grandes grupos e setores hegemônicos nacionais e internacionais.

É necessário, empreender uma análise da essência do movimento político dos governos do PT para a política educacional brasileira, logo, desvelar os reais interesses com este setor, ou seja, a conditio sine qua non que impulsionaram os mecanismos da educação privada/mercantil e, muito embora haja desmonte das universidades públicas, os setores subalternos compreendem um avanço com a expansão deste nível de ensino, para isso, é necessário localizar os sujeitos que atuam neste âmbito.

\section{A política educacional da Hegemonia às Avessas}

Embora os elementos postos pela noção das orientações dos organismos internacionais para a educação dos países periféricos, a política educacional no que tange sua inflexão frente às determinações heterônomas mantêm-se divergente com as reais necessidades da particularidade capitalista do Brasil ${ }^{9}$, portanto, à mercê dos desígnios dos setores hegemônicos internacionais.

Concernente os governos petistas ao longo de três governos concluídos e um interrompido pelo golpe de Estado efetuado pelos setores mais conservadores da burguesia local, identificamos, as várias políticas públicas engendradas para a área educacional, todavia, a forma dessas políticas vai além do conteúdo o qual é disseminado. É preciso deixar explícito que, reconhecemos, por vezes, os aspectos positivos da aplicação de uma dada política educacional, muito embora, reconheçamos, por seu turno, os aspectos negativos que, em grande medida, se fazem subjacentes, não se mostrando no campo da aparência, contudo, apenas no âmbito da essência, tendo, deste modo, a necessidade de investigar a fundo o real sentido que estas políticas trazem para a realidade social concreta. 
É lícito observar, que o conteúdo das políticas educacionais exposto no discurso hegemônico governamental tem produzido uma série de reflexões, mormente no ensino superior, que tendem a se moldarem às concepções ideológicas apologéticas dominantes no marco histórico em tela. Deste modo, corrobora-se a assertiva marxiana/engelsiana ' $n$ ' $A$ ideologia alemã": "As ideias da classe dominantes são, em todas as épocas, as ideias dominantes, ou seja, a classe que é o poder material dominante da sociedade é, ao mesmo tempo, o seu poder espiritual dominante" (MARX; ENGELS, 2010, p. 72). Assim, ao passo que apenas contribuições imediatas e paliativas das políticas educacionais são disseminadas, o real objetivo subjacente é escamoteado.

Foi nessa acepção, que os governos Lula da Silva e Dilma Rousseff conseguiram grande apoio popular durante o exercício de seu governo. ${ }^{10}$ No limite, expressamos acordo com a concepção de "hegemonia às avessa" empreendida por Francisco de Oliveira (2010), à qual denota que, de certo modo, é a partir da compreensão de esta se tratar de um modo de dominação que se diferencia de todos os modos precedentes na história brasileira. $\mathrm{O}$ autor assevera que há um consentimento passivo dos setores subalternos. Portanto, na concepção de Silva Júnior, Anelli Júnior e Mancebo (2010, p. 116) "não se trata de os trabalhadores consentirem que os representantes do capital governem o país", contudo o que ocorre é o contrário, para isso emprega-se o conceito de "avessas", "é o capital que consente que os supostos representantes do trabalho governem o país em seu nome. Tratase de um fenômeno único".

Destarte, várias foram ás políticas implementadas que em sua essência possuíam caráter focalista e compensatório. ${ }^{11}$ No que concerne à educação em geral, diversas ações e políticas públicas foram efetivadas. A despeito do conteúdo democratizante propagado no discurso oficial, na sua essência, pode-se localizar elementos que decorrem grandes implicações qualitativas para o setor empresarial, no que toca ao ensino privado/mercantil em detrimento do ensino público. Compreendendo essa lógica, partimos para análise das conexões do movimento Todos Pela Educação (TPE) - setor intelectual da política educacional de Lula da Silva e Dilma Rousseff - com o documento Pátria Educadora, assim discorrendo sobre a constituição das metas para a educação brasileira às quais foram elaboradas por este movimento, tendo como ponto de chegada o documento Pátria Educadora e sua ampliação a lema governamental no bojo das contradições estruturais com o PNE.

No que tange o TPE em sua raiz podemos contextualizar, em um plano histórico, que é a partir da década de 1990 que o setor empresarial nacional organizou documentos e fóruns que indicavam interesse na constituição de uma agenda educacional direcionada para "produção de uma nova sociabilidade mais adequada aos interesses privados do grande capital nacional e internacional". O que se pretende, nessa perspectiva, é reformar a educação para que atenda as demandas do capital. Assim, pretende-se efetivar a importação da "suposta" eficiência do modelo empresarial, bem como "repor a função social da educação e da escola destituindo-se, contudo, do seu caráter público" (SHIROMA; GARCIA; CAMPOS, 2011, p. 227).

Cabe salientar que:

As reivindicações das lutas pela democratização da educação são incorporadas e ressignificadas e o empresariado brasileiro empregando o discurso de 'educação para todos e todos pela educação' apresenta propostas alinhadas com as reformas educacionais implementadas em vários países europeus e latino-americanos a partir da década de 1990. Tais reformas anunciavam como objetivo central a melhoria da qualidade da educação, o que inclui ampliação de jornada escolar, universalização 
do atendimento, propostas de avaliação em larga escala, incentivos à realização de parcerias externas buscando apoio às atividades educacionais, investimento em formação inicial e continuada e valorização dos profissionais da educação, dentre outras questões. (BERNARDI; ROSSI; UCZACK, 2014, p. 04).

A partir do evento realizado pelo $\mathrm{TPE}^{12}$, o artigo publicado por uma de suas intelectuais simboliza uma síntese do conteúdo do evento:

Só a educação de qualidade pode formar a base de um novo projeto de país, mais justo e mais desenvolvido. Foi exatamente esse o espírito do encontro na Bahia: ao analisar o triste cenário no Brasil e na América Latina, os 250 participantes do evento chegaram à conclusão de que a educação é, neste momento, a mais importante política pública e que assegurar a sua qualidade, especialmente para os menos favorecidos, constitui o melhor instrumento para reduzir nossas históricas desigualdades sociais. [...] É a crença de que a educação deixará de ser pauta de importância secundária apenas quando todos os setores fizerem a sua parte de forma integrada e sinérgica. Pela primeira vez, um grupo de lideranças, apoiado por organizações da sociedade civil e em sintonia com os governos, decidiu juntar esforços em torno de um grande projeto educacional para o país. Como demonstração de vontade, a maioria dos presentes subscreveu sua participação no movimento "Compromisso Todos Pela Educação" [...]. Na prática, a adesão significa colocar energia e recursos no cumprimento da missão de efetivar o direito à educação de qualidade para que, em 2022, bicentenário da Independência do Brasil, todas as crianças e jovens tenham acesso a um ensino básico que os prepare para os desafios do século 21 (VILELLA, 2006, p.03).

O TPE pretende monitorar e divulgar a educação nacional, assim, passando a intervir nos padrões que são considerados detentores de qualidade, divulgando, deste modo, os padrões considerados sucessos em gestão, portanto, que fazem usos das inovações tecnológicas e didáticas propiciadas por seus parceiros. Todavia, o TPE avalia que, o Brasil, não obstante os esforços, não mostra eficácia no que toca as políticas educacionais em função de duas causas: "incapacidade de definir mecanismos de acompanhamento e de avaliação; imprecisão no estabelecimento de objetivos quantitativos parciais e finais de seus projetos". (MARTINS, 2009, p. 10). Noutras palavras, na concepção do TPE, os propósitos políticos bons seriam afetados negativamente pela incapacidade técnica e operacional governamentais, bem como pela escassez de instrumentais democratizantes de controle social.

Em total acordo com a proposta exposta anteriormente, o governo Lula da Silva por meio do Ministério da Educação (MEC), lançou o Plano de Desenvolvimento da Educação (PDE), incorporando, dessa forma, o Plano de Metas Compromisso Todos pela Educação, Decreto $n^{\circ}$ 6.094/07 (BRASIL, 2007). O PDE pressupõe o desenvolvimento da educação nacional, realçando que, é necessário certificar a conformação da política educacional ao acordo erigido pelo setor empresarial do Brasil.

Em acréscimo, é possível identificar o interesse do TPE pela educação básica, o que se afina com os interesses do BM, deixando a educação superior a cargo da iniciativa privada. O PDE traz elementos para a educação superior, a saber, o programa que ganha destaque se trata do Decreto $n^{\circ}$ 9.096/07, que institui o Programa de Apoio a Planos de Reestruturação e Expansão das Universidades Federais (REUNI). Este programa buscou 
efetivar uma expansão das universidades federais no tocante a ampliação do número de matrículas discentes em 30\%, aumento da relação aluno/professor de dezoito por um, aumentar gradativamente a taxa de conclusão para $90 \%$, além de estabelecer um contrato de gestão através do plano de metas, o que atinge diretamente a autonomia universitária prevista no art. 207 da constituição (BRASIL, 1988). Todo esse processo seria realizado no curso de cinco anos, tendo em vista o aumento de $20 \%$ do financiamento, sendo este condicionado pela capacidade orçamentária do MEC. No que diz respeito à expansão do número de matrículas nas universidades federais, a Tabela 1 traz dados que explicitam a evolução do número de matrículas nas instituições de educação superior (municipal, estadual, federal e privada), e utilizamos o período demonstrativo de 2007 à 2012 por se tratar do período de operacionalidade do Reuni, assim, possibilitando empreender um balanço dessa expansão.

Tabela 1 - Evolução do Número de Matrículas de Graduação em IES Públicas, segundo a Categoria Administrativa (2007-2012).

\begin{tabular}{|c|c|c|c|c|c|c|}
\hline \multirow{3}{*}{ Ano } & \multicolumn{6}{|c|}{ Número de ingressantes } \\
\hline & \multirow[t]{2}{*}{ Total Geral } & \multicolumn{4}{|c|}{ Pública } & \multirow[t]{2}{*}{ Privada } \\
\hline & & Total & Federal & Estadual & Municipal & \\
\hline 2007 & 2.138 .241 & 416.178 & 193.919 & 176.047 & 46.212 & 1.722 .063 \\
\hline 2008 & 2.336 .899 & 538.474 & 211.183 & 282.950 & 44.341 & 1.798 .425 \\
\hline 2009 & 2.065 .082 & 422.320 & 253.642 & 133.425 & 35.253 & 1.642 .762 \\
\hline 2010 & 2.182 .229 & 475.884 & 302.359 & 141.413 & 32.112 & 1.706 .345 \\
\hline 2011 & 2.346 .695 & 490.680 & 308.504 & 146.049 & 36.127 & 1.856 .015 \\
\hline 2012 & 2.747 .089 & 547.897 & 334.212 & 152.603 & 61.082 & 2.199 .192 \\
\hline Variável & 28,5 & 31,6 & 72,3 & $-13,3$ & 32,2 & 27,7 \\
\hline
\end{tabular}

Fonte: Inep/Mec (2012).

De acordo com os dados expostos na Tabela 1, observa-se o crescimento relativo no número de matrículas discentes na educação superior pública em sua totalidade, representando um aumento de 31,6\% de aumento nas instituições públicas de ensino superior, sendo que, por seu turno, as IFES representaram um aumento da ordem de $72,3 \%$ no período da operacionalidade do REUNI. No que tange o aumento relativo do número de matrículas nas IPES ficou na ordem dos $27,7 \%$, contudo, a quantidade de vagas nas IPES é demasiadamente superior frente às instituições públicas, logo, em 2012 as IPES ofertaram 2.199.192 vagas discentes, ao passo que todas as instituições públicas ofertaram 547.897 vagas.

No tocante o ensino superior privado/mercantil, observa-se grande concentração de matrículas em termos comparativos frente às IES públicas. Nessa acepção, leva-se em conta além da liberalização dos serviços educacionais pós-LDB de 1996, as intervenções dos programas que assumem no discurso governamental uma roupagem de democratização do ensino superior brasileiro. Consoante a Tabela 2, percebe-se o total de recursos do orçamento da união que foram repassados para a operacionalidade do Fundo de Financiamento Estudantil (FIES), bem como os gastos tributários do Programa Universidade para Todos (ProUni). 
Tabela 2 - Gastos tributários da união com o ProUni (2005-2014); despesas do orçamento da união com o Fies (2003-2014).

\begin{tabular}{ccc}
\hline Ano & FIES & ProUni \\
\hline $\mathbf{2 0 0 3}$ & 1.341 .626 .724 & - \\
$\mathbf{2 0 0 4}$ & 1.237 .629 .607 & - \\
$\mathbf{2 0 0 5}$ & 1.305 .932 .989 & 177.086 .854 \\
$\mathbf{2 0 0 6}$ & 1.455 .157 .896 & 343.789 .715 \\
$\mathbf{2 0 0 7}$ & 1.490 .535 .757 & 535.882 .639 \\
$\mathbf{2 0 0 8}$ & 1.699 .753 .769 & 631.266 .786 \\
$\mathbf{2 0 0 9}$ & 1.922 .681 .718 & 735.511 .137 \\
$\mathbf{2 0 1 0}$ & 2.276 .285 .230 & 762.939 .552 \\
$\mathbf{2 0 1 1}$ & 3.052 .490 .346 & 698.659 .132 \\
$\mathbf{2 0 1 2}$ & 3.962 .044 .038 & 890.479 .903 \\
$\mathbf{2 0 1 3}$ & 8.372 .431 .851 & 830.190 .930$. \\
$\mathbf{2 0 1 4}$ & 12.528 .635 .389 & 625.001 .269 \\
Total & $\mathbf{4 0 . 6 4 5 . 2 0 5 . 3 1 4}$ & $\mathbf{5 . 4 0 0 . 6 1 6 . 9 8 7}$ \\
\hline
\end{tabular}

Fonte: Senado Federal (Portal do Orçamento).

Observa-se nos dados (Tab. 2) a dimensão do total geral de recursos públicos que são canalizados, bem como deixados de arrecadar das Instituições de Ensino Superior privado. Em termos financeiros, a soma do total dos recursos do FIES e do ProUni resulta em R \$ 46.045.822.301,00. Ou seja, ultrapassa a ordem dos 46 bilhões. Se compararmos este valor com o total de recursos investidos nas IFES no mesmo período analisados iremos constatar, conforme Reis (2016), que as IFES receberam um total de R\$ 346.555.418.940,00 no período de 2003-2014. Deste modo, verifica-se que as IES privadas com o ProUni e o FIES adquirem do orçamento público 13,3\% frente o orçamento das IFES.

Com efeito, é nesse cenário que conseguimos, a rigor, caracterizar com mais propriedade a diluição das fronteiras entre o público e o privado, logo, se educação é interpretada como um serviço público, as IES privadas estão ofertando este tipo de serviço, o que na concepção governamental, estas também devem ser financiadas pelo Estado, configurando, deste modo, a educação pública não-estatal.

Nessa acepção, com o término do governo Lula da Silva e início de governo Dilma Rousseff, o PDE perde sua validade por se tratar de uma política de governo. Todavia, as políticas adotadas por Dilma se mostraram como continuísmo do governo precedente, culminando na elaboração de um novo PNE, bem como no documento referente ao lema governamental adotado pelo então governo, a saber, Pátria Educadora. Todavia, trataremos esse ponto, de modo mais preciso a seguir.

\section{Contrastando analiticamente a proposta Pátria Educadora}

No bojo das contradições intrínsecas ao governo Dilma Rousseff, apreendemos o movimento que se desencadeou ao longo do primeiro mandato, no que diz respeito às políticas educacionais. No primeiro momento houve uma ruptura com os programas de governo como, por exemplo, o Decreto 9.096/07 que instituiu o programa REUNI, no entanto, além de momentos de ruptura, o que prevaleceu foi uma linha de continuidades com as políticas do governo Lula da Silva, mormente seu compromisso com o setores empresariais e a dissimulação do real conteúdo de seus projetos a partir de medidas compensatórias.

Uma das contradições crônicas se trata da força da Secretaria de Assuntos Estratégicos (SAE) frente ao MEC, a ponto de elaborar um documento no qual destituiu 
este último de autonomia sobre seu setor, assim a educação nacional foi compreendida, no governo Dilma Rousseff - não apenas nesse governo, mas em função de nossa crítica estar focada nesse objeto, este governo será tratado com destaque -, como uma estratégia para o próprio desenvolvimento do país no que tange os elementos oriundos da teoria do capital humano de Shultz (1973). Em acréscimo, constatamos que a SAE nos últimos cinco anos, tem sido a porta-voz da política dos reformadores empresariais da educação.

Ressaltamos o elemento inovador que se trata do lema governamental "Pátria Educadora" conferir prioridade para a educação nacional, o que outrora não era reiterado por mais que políticas públicas e intervenções estatais sempre estiveram presentes - como prioridade dos governos anteriores. O lema governamental se apresenta a partir do documento elaborado pelo ministro da SAE, Roberto Mangabeira Unger. Todavia, é nítido até para o mais míope, que se trata uma de "proposta preliminar" à qual é direcionada para a Educação Básica. Em verdade, o ensino superior ilustra, apenas, duas passagens em todo o documento, sendo caracterizado apenas como uma etapa consequente do processo de escolarização daqueles que dão continuidade em seu processo formativo. Para esclarecer, a Associação Nacional de Política e Administração da Educação (ANPAE) ilustra bem esse caráter de apresentação da proposta Pátria Educadora:

O Documento "Pátria educadora: A qualificação do ensino básico como obra de construção nacional", é apresentado como uma proposta preliminar para discussão. Também é apresentado como portador de "diretrizes de um projeto nacional de qualificação do ensino básico". Mesmo restringindo-se ao "ensino básico", não contemplando a educação superior e às demais modalidades de educação, o documento busca apresentar "A TAREFA" (ideário do projeto) e as "INICIATIVAS" (conjunto de ações) que deverão nortear as políticas educacionais do atual governo federal para o "ensino básico", o que restringe o Lema Pátria Educadora. (ANPAE, 2015, p. 02).

Parece-nos lícito, compreender que o documento em tela, incorporado ao lema governamental, dando ênfase para a educação básica, corrobora, a rigor, as orientações do BM para o padrão de educação para os países dependentes da periferia capitalista. Ou seja, a diretrizes educacionais vão de encontro com as orientações dos organismos internacionais, no que diz respeito ao protagonismo da educação básica, em especial aos "degraus inferiores do ensino básico" (BRASIL, 2015, p. 05).

A partir de uma análise dos elementos que constituem o documento Pátria Educadora, percebe-se que não há nenhuma menção às Conferências Nacionais de Educação (CONAE) que, por sua vez, foram produzidas pelo próprio governo, contudo, são irremediavelmente ignoradas. Outra constatação se trata do PNE (2014-2024) não possuir lugar de destaque, apenas de cooperação para tornar factíveis específicas diretrizes/ações. No limite, a SAE com a proposta Pátria Educadora suprime, deste modo, a política educacional brasileira produzida ao longo dos últimos anos.

Além destes elementos, no documento é constatado um caráter elitista:

Não há na história do Brasil ou do mundo um único exemplo de grande mudança em educação que não tenha sido liderada por um grupo coeso e vanguardista, com posição dentro do Estado ou influência forte sobre as políticas públicas. Em cada caso de transformação, tal grupo formou ideário que definiu trajetória. Traduziu o ideário em iniciativas que representaram os primeiros passos de caminho ambicioso. E construiu, 
com base no ideário e nas iniciativas, mística nacional capaz de despertar adesão e arrebatamento. (BRASIL, 2015, p. 03).

Destarte, a partir dessa compreensão, o ministro da SAE compreende que para a execução de tal intento é necessário uma "vanguarda pedagógica", uma ótima atribuição para o TPE, consoante o documento:

De todos os obstáculos a enfrentar para dar prosseguimento a agenda como esta, que propõe transformação profunda no ensino básico, com consequências também para o ensino superior, o mais grave é a falta, entre nós, de vanguarda pedagógica. [...] Professores e diretores da rede pública e militantes da sociedade civil, teóricos da educação e reformadores práticos podem juntos compor esta linha de frente, capaz de convergir em torno da agenda. [...] A vanguarda pedagógica precisa ser a principal portadora deste projeto. (BRASIL, 2015, p. 20).

Essa exposição coloca a iluminação que estava faltando para a educação brasileira, contudo, ainda falta a vanguarda propagada. Freitas (2015) concebeu críticas pertinentes ao documento em análise, e acerca da citação exposta acima, o autor assevera: "não terá dificuldade o governo Dilma em conseguir [...] adesão do Movimento Todos Pela Educação para sua vanguarda”. E continua: “o que se quer é encontrar uma vanguarda que seja portadora de ideias centrais idênticas às que já estão prontas e que se una com o objetivo de contribuir apenas a implementação da agenda" (FREITAS, 2015, s/p.).

Exposto isto, a ANPAE, publicou uma análise do documento, em que se posiciona criticamente acerca do conteúdo imbuído do lema Pátria Educadora, bem como ressalta a necessidade dos elementos constituídos na dinâmica da CONAE e do PNE para com este lema:

Entendemos que o lema "Pátria Educadora" deve ter seu ideário construído a partir dos documentos finais das Conferencias Nacionais de Educação (CONAE 2010 e 2014), aprovados depois de ampla discussão dos educadores brasileiros. Entendemos também que as ações básicas e estratégias para o Lema "Pátria Educadora" já estão inseridos no PNE 2014-2024, por meio de metas e estratégias, mesmo com contradições que ainda precisam ser superadas. Portanto, a efetivação do PNE e do Sistema Nacional de Educação deve se dar no contexto da participação social, do direito à educação, da gestão democrática e da regulamentação e efetivação do Regime de Colaboração ou Cooperação Federativa. (ANPAE, 2015, p. 1).

Cabe ressaltar que, após repercussão desses elementos, o ministro da SAE, buscou subterfúgios para legitimar sua proposta, além de expor resumidamente a estrutura da proposta Pátria Educadora, o ministro, solicitou a cooperação a partir de críticas e orientações em geral atribuídas ao documento. No final da carta em que foi exposto isso, é notável o caráter cooperativo de construção coletiva, no dizer do ministro: "A Pátria Educadora só viverá como obra de construção nacional e projeto de Estado a que todas as partes da nação contribuam". (UNGER, 2015, p. Única).

Com efeito, é possível localizar uma contradição no conteúdo exposto na carta do ministro. Não obstante a propalada "construção nacional" a qual atribui na elaboração da proposta Pátria Educadora, esta mesma proposta foi elabora pela SAE que, por sua vez, ultrapassa as competências inerentes ao MEC, bem como as proposições dos educadores 
brasileiros ao longo de anos em defesa de uma escola pública com qualidade e um Sistema Nacional de Educação. Ressaltamos, também, a ênfase dada, a priori, para a educação básica, o que nos parece que - sob a ótica da Pátria Educadora - seria a qualificação deste nível educacional uma possível resolução para a crise educacional brasileira preconizada (BRASIL, 2015). No tocante, em audiência pública Mangabeira Unger explicita ${ }^{13}$ - após críticas discorridas acerca da proposta Pátria Educadora - que este documento busca, no limite, subsidiar a efetivação das ações do PNE (2014-2024), assim, reduzindo sua proposta como mero braço auxiliar.

Compreendemos que, assim, a concepção da "qualificação do ensino básico" está calcada nas orientações do BM para o sistema educacional dos países periféricos, deixando a educação superior sob a regência da iniciativa privada, cabendo o Estado apenas supervisionar. Esta noção confere a desresponsabilização do Estado para o ensino superior, logo, no bojo das relações da mundialização do capital, este nível de ensino é compreendido como nicho mercadológico para extração lucrativa, portanto, ficando à mercê dos reformadores empresariais da educação.

\section{Considerações finais: o local da educação superior na Pátria Educadora}

A educação superior no documento da proposta Pátria Educadora, como foi visto anteriormente, não é mencionada de modo preciso, logo, a ênfase da proposta é dada prioritariamente à educação básica, o que nos leva a refletir acerca dos apontamentos dos organismos internacionais sobre a política educacional da periferia capitalista.

Os condicionantes acerca da política de educação superior no governo Dilma Rousseff, estão centrados nas metas e estratégias do PNE (2014-2024), o que Mangabeira Unger alegou ser a política educacional vigente a nível nacional. Nesse sentido, identificamos linhas de continuidade com a política educacional do governo Lula da Silva, que outrora a partir de suas atribuições e acordos com setores empresariais (RODRIGUES, 2007), assim como os organismos internacionais, fez uso de política de governo para efetivar seus intentos na educação superior.

O elemento inovador no governo interrompido de Dilma Rousseff foi a transformação do que antes se apresentava como política de governo passando a ser apresentado como política de Estado, atingindo alcance superior. Deste modo, trazendo o velho com roupagem de novo.

Desde 2011, estava em andamento a proposta do novo PNE - Projeto de Lei 8.035/2010, exposto pelo governo Dilma. Um projeto muito polêmico, que vivenciou discussões, debates e conferências. Todavia, apenas em 2014 o PNE veio ser implementado pela Lei ${ }^{\circ}$ 13.005/14. O atual PNE traça 20 metas e uma série de estratégias para a educação brasileira nos próximos 10 anos. Uma apreciação mais meticulosa desvela que este documento procura organizar os principais projetos educacionais instituídos desde 2004 pelo governo Lula da Silva. [...] A compreensão de avaliação que está subjacente possui um cunho de regulação e controle como também de confirmação à desqualificação dos processos de formação humana ou a sua minimalização, doravante, o modelo de competências calcado em habilidades e atitudes solicitadas pelos novos modelos de trabalho e de consumo que se traduz em instrumentalismo (DE PAULA, 2015, p. 141). 
Em síntese, as políticas educacionais que estiveram em operação no governo Lula da Silva surgiram em uma nova processualidade com um tempo mais amplo de execução de seu escopo. Concernente às metas que tratam, em especial, o ensino superior - metas 12,13 e 14, respectivamente -, abordam:

[...] da elevação da taxa de matrícula neste nível de ensino, da qualificação do corpo docente e da elevação do número de matrículas na pós-graduação stricto sensu (mestrado e doutorado). As estratégias para alcançar as metas do PNE estão relacionadas com as metas de expansão e reestruturação político-pedagógica do REUNI; a expansão do FIES, para a graduação e a pós-graduação stricto sensu, inclusive a distância; o aperfeiçoamento do Sistema Nacional de Avaliação da Educação Superior (Sinaes); e a ampliação do Ensino a Distância/EAD através da Universidade Aberta do Brasil/UAB. (LIMA, 2015, p. 41-42).

Outrossim, é o ressurgimento do programa REUNI, o qual busca expandir o número de matrículas discentes, aumentar a relação professor/aluno, flexibilizar currículos, contudo, não ocorrendo mais apenas no subsistema federal de educação superior, todavia, cabendo operacionalidade em outras instâncias institucionais de ensino superior, estadual e municipal. Muito embora essas políticas se mostrem, aparentemente, como medidas democratizantes, todavia, em sua essência atendem interesses que estão escamoteados pelo conteúdo assistencialista imbuído no bojo da preconização do próprio PNE. Ora, é possível identificar uma contradição no processo de implantação do PNE, pois para efetivar tais ações o decorrente financiamento deve estar condizente com a realidade. No conteúdo da própria lei $\mathrm{n}^{\mathrm{o}}$ 13.005/14 que aprova o PNE (2014-2024) é apresentado na meta 20: "ampliar o investimento público em educação pública de forma a atingir, no mínimo, o patamar de 7\% [...] (do) PIB do País no $5^{\circ}$ [...] ano de vigência desta Lei e, no mínimo, o equivalente a 10\% [...] do PIB ao final do decênio" (BRASIL, 2014). No entanto, o que se pretendia na concepção dos educadores brasileiros a partir da CONAE era de início obter $10 \%$ do PIB revestidos para a educação pública. O que na prática não se realizou, logo, foi dada atenção a agenda do TPE, bem como excluir o conceito público, deste modo, atribuindo à educação um novo sentido, passando a ser compreendido também como educação não-estatal, o que representa, noutros termos, financiamento público para instituições privadas, em especial, na educação superior.

Centrando-nos no ensino superior, percebe-se que os investimentos não estão sendo canalizados conforme se esperava, o que se observa, é a redução do orçamento direcionado para estas instituições, sem, contudo, afetar os estabelecimentos privados/mercantis. $\mathrm{O}$ arrefecimento no investimento em Educação em 2015 ultrapassou a margem dos R \$ 11 bilhões de seu orçamento, em virtude da efetivação do pacote de cortes no orçamento para garantir o pagamento dos juros e amortizações da dívida pública ao setor financeiro (ANDES, 2015). Todavia, o ProUni e, em especial o FIES, continuam arrecadando amplos montantes de recursos para as instituições privada/mercantis de ensino superior.

Com efeito, o processo desencadeado no governo Dilma Rousseff aprofundou aquele que outrora se fez presente no governo Lula da Silva, a lógica da hegemonia às avessas corrobora a compreensão das políticas focalistas e compensatórias na consolidação do consentimento subalterno das classes trabalhadoras, no que toca as medidas paliativas, o governo em tela conseguiu desmobilizar/despolitizar estes setores a partir de ações focalizadas e que compensem os resultados negativos engendrados por outras medidas governamentais. Nessa acepção, a lógica da expansão que o PNE (2014-2024) traz baseado no REUNI, desvela a intenção da certificação em larga escala, bem como a privatização 
deste nível de ensino a partir das compras de vagas públicas em instituições privada/mercantis, como também a expansão sem limites dessas instituições, o que efervesce, necessariamente, o mercado educacional a partir de sua acelerada mercadorização (SGUISSARDI, 2008).

Esse contexto é, precisamente, alinhado com a lógica da mundialização capitalista, isto é, a compreensão da educação - dentro dos limites do neoliberalismo, em que áreas sociais são compreendidas como mercadorias - se trata de um nicho de mercado promissor para o capital que, por seu turno, a legislação brasileira pós-LDB 9.394/96 (BRASIL, 1996) já contribui nesse quesito, doravante, Decreto $\mathrm{n}^{\circ}$ 2.306/97, que "reconhecia a educação superior como um bem de serviço comercializável, isto é, como objeto de lucro ou acumulação" (SGUISSARDI, 2008, p.1000). Deste modo, nos acontecimentos que se deram como necessidade da própria particularidade capitalista brasileira, decorreu na inserção do capital financeiro, dos grandes fundos de investimento no chamado mercado educacional nacional, e na inserção de instituições privadas de ensino superior na Bolsa de Valores de São Paulo (BOVESPA).

Nesse sentido, com a Pátria Educadora, dando atenção especial para o ensino básico, assim como desresponsabilizando o Estado com a educação superior, questionamos: a quem serve a Pátria Educadora? A expansão das vagas nas universidades públicas a partir do PNE (2014-2024) sem o financiamento correspondente, não estaria contribuindo, significativamente para a precarização das universidades? E o trabalho docente, sem concursos que atendam essas demandas, estaria aprofundando sua intensificação? Os interesses mercantis acerca da educação superior são sustentados pelo próprio Estado?

Com essas questões lançadas, tivemos o objetivo de, a partir da compreensão do universal, buscar compreender a particularidade hodierna da política de educação superior brasileira no que toca seu alinhamento com o capital internacional. É necessário explicitar que não se trata de encerrar o assunto nesta pequena contribuição para o debate, mas, estimular os educadores, pesquisadores, movimentos sociais a si questionarem sobre os desdobramentos da educação brasileira, sob um lema governamental no qual a forma ultrapassa o conteúdo, em que a educação pública não ilustra, a rigor, prioridade.

\section{Referências}

ANDES. Governo anuncia mais cortes, adiamento de reajuste e congelamento de concursos. 2015.2 Disponível em: $<$ http://grevenasfederais.andes.org.br/2015/09/15/governo-anuncia-mais-cortes-adiamentode-reajuste-e-congelamento-de-concursos/> Acesso em: 01 dez. 2015.

AMARAL, M. P.; Política pública educacional e sua dimensão internacional: abordagens teóricas. Educação e Pesquisa (USP. Impresso), v. 36, p. 39-54, 2010.

ASSOCIAÇÃO NACIONAL DE POLÍTICA E ADMINISTRAÇÃO DA EDUCALÇÃO. Análise do documento Pátria Educadora. (mimeo), 2015.

BANCO MUNDIAL. Relatório sobre desenvolvimento mundial 1997: o Estado num mundo em transformação. Washington/DC: Banco Mundial, 1997.

BASTOS, Remo Moreira Brito; ROCHA, Antonia Rozimar Machado. A política educacional do Banco Mundial para os países periféricos como expressão da geopolítica do conhecimento. Contribuciones a las Ciencias Sociales, v. 140, p. Única, 2015. Disponível em: < http://www.eumed.net/rev/cccss/2015/01/geopolitica.html> Acesso em: $08 \mathrm{dez}$. 2015 . 
BERNARDI, L. M.; ROSSI, A. J.; UCZACK, L. H. Do Movimento Todos pela Educação ao Plano de Ações Articuladas: empresários interlocutores e clientes do Estado. In: X ANPED Sul - Seminário de Pesquisa em Educação da Região Sul, Florianópolis, 2014. Disponível em: 〈http://xanpedsul.faed.udesc.br/arq_pdf/596-0.pdf> Acesso em: 30 de nov. 2015.

BRASIL. Constituição Federal. Brasília, 1988.

Decreto no 6.096, de 24 de abril de 2007. Institui o Programa de Apoio a Planos de Reestruturação e Expansão das Universidades Federais - REUNI. [S.1.], 2007a. Disponível em: <http://www.planalto.gov.br/ccivil_03/_ato20072010/2007/decreto/d6096.htm>. Acesso em: 6 nov. 2015.

. MEC. O Plano de Desenvolvimento da Educação: razões, princípios e programas. Brasília: MEC, 2007b. Disponível em: <http://portal.mec.gov.br/arquivos/livro/index.htm>. Acesso em: 11 nov. 2015.

Lei 13.005, de 25 de junho de 2014. Aprova o Plano Nacional de Educação PNE e dá outras providências. Disponível em: <http://http://presrepublica.jusbrasil.com.br/legislacao/125099097/lei-13005-14>. Acesso em: 15 de nov. de 2015.

Secretaria de Assuntos Estratégicos. Pátria Educadora: qualificação do ensino básico como obra de construção nacional. 2015. Disponível em: < https://www.google.com.br/url?sa=t\&rct=j\&q=\&esrc=s\&source=web\&cd=1\&cad=rja\&ua $\mathrm{ct}=8 \& v e d=0$ ahUKEwitktSLwqPLAhVTlpAKHTK6AEYQFggcMAA\&url=http $\% 3 \mathrm{~A} \% 2 \mathrm{~F}$ \%2Fcedes.preface.com.br\%2Fdl\%2F1IAKTzzA0_MDA_7e05e_\&usg=AFQjCNERabAh NdMMKFqYYPJFwr0CA2QG3w>. Acesso em: 02 fev. 2016.

DE PAULA, Alisson Slider do Nascimento. A Degradação da Universidade: a educação superior a serviço do capital. Universidade e Sociedade, v. 56, p. 58-71, 2015.

FERNANDES, Florestan. Universidade brasileira: reforma ou revolução? São Paulo: Alfa-Omega, 1975.

FREITAS, Luiz Carlos de. Pátria Educadora II. 2015. Disponível em: < http://avaliacaoeducacional.com/2015/04/23/patria-educadora-ii/>. Acesso em: 05 fev. 2016.

INSTITUTO NACIONAL DE ESTUDOS E PESQUISAS EDUCACIONAIS ANÍSIO TEIXEIRA - Inep. Censo da Educação Superior 2012. Brasília, DF: Inep, 2013. Disponível em: <http://portal.inep.gov.br/superior-censosuperior-sinopse>. Acesso em: 18 nov. 2015.

LIMA, Kátia Regina de Souza. O Programa Reuni e os desafios para a formação profissional em Serviço Social. Rev. katálysis [online], vol.16, n.2 ISSN 1414-4980, 2011. Disponível em: < http://www.scielo.br/scielo.php?script=sci_arttext\&pid=S141449802011000100010> Acesso em: 02 jan. 2016.

. Plano Nacional de Educação 2014-2024. Universidade e Sociedade, v. 55, p. 32-43, 2015.

. Expansão e reestruturação das universidades federais e intensificação do trabalho docente: o programa REUNI. Revista de Políticas Públicas (UFMA), v. Especial, 2012.

Contra-reforma da educação nas universidades federais: o REUNI na UFF. Universidade e Sociedade, n. 44, p. 147-157, 2009. 
MARTINS, A. A educação básica no século XXI: o projeto do organismo "Todos pela Educação". Práxis Educativa, Ponta Grossa, v. 4, n. 1, jan./jun. 2009.

MARX, Karl. O capital: crítica da economia política. Rio de Janeiro: Civilização Brasileira, 2013.

MARX, Karl; ENGELS, Friedrich. A Ideologia Alemã. São Paulo: Expressão Popular, 2010.

MÉSZÁROS, Istvan. A crise Estrutural do Capital. São Paulo: Boitempo, 2008.

MINTO, Lalo Watanabe. A educação da miséria: particularidade capitalista e educação superior no Brasil. São Paulo: Outras Expressões, 2014.

NISHIMURA, Shin Pinto. A precarização do trabalho docente como necessidade do capital. Universidade e Sociedade, v. 56, 2014.

OLIVEIRA, Francisco. Hegemonia às avessas. In: OLIVEIRA, Francisco; BRAGA, Ruy; RIZEK, Cibele (Orgs). Hegemonia às avessas. São Paulo: Boitempo, 2010.

REIS, LUIZ FERNANDO. Dívida Pública, Política Econômica e o financiamento das universidades federais nos governos Lula e Dilma (2003-2014). Universidade e Sociedade (Brasília), v. 57, p. 16-35, 2016.

RODRIGUES, José. Os empresários e a educação superior. Campinas: Autores Associados, 2007.

SENADO FEDERAL. Demonstrativos da Execução Orçamentária: 2003-2014. Portal

Orçamento (Siga Brasil). Disponível em: <http://www9.senado.gov.br/portal/orcamento_senado/SigaBrasil>. Acesso em: 10 jan. 2016.

SGUISSARDI, Valdemar. Modelo de expansão da educação superior no Brasil: predomínio privado/mercantil e desafios para a regulação e a formação universitária. Educ. Soc. [online]. vol.29, n.105, 2008.

SGUISSARDI, Valdemar.; SILVA JÚNIOR, João dos Reis. O trabalho intensificado nas federais: pós-graduação e produtivismo acadêmico. São Paulo: Xamã, 2009.

SHIROMA, Eneida Otto; GARCIA, Rosalba Maria Cardoso; CAMPOS, Roselane Fatima. Conversão das "almas" pela liturgia da palavra: uma análise do movimento Todos pela Educação. In: BALL, Stephen J.; MAINARDES, Jefferson. Políticas educacionais: questões e dilemas. São Paulo: Cortez, 2011.

SCHULTZ, Theodore. O Capital Humano. Rio de Janeiro: Zahar, 1973.

SILVA JÚNIOR, J. R.; ANELLI JÚNIOR, L. C.; MANCEBO, D. O lulismo e a mudança da natureza do trabalho docente. Revista Eletrônica de Educação (São Carlos), v. 8, p. 106-118, 2014.

UNGER, Roberto Mangebeira. Carta Pátria Educadora. 2015. Disponível em: <http://www.anped.org.br/forum/uploads/Uploader/17/6159be4fd09c911934df528b80f6b9 .pdf> Acesso em: 13 nov. 2015.

VILELLA, Milú. Hora de pensar na educação. Jornal Folha de São Paulo, Tendências/Debates, p.03, 11 de julho de 2006. 


\section{Notas}

${ }^{1}$ Doutorando pelo Programa de Pós-Graduação em Educação da Universidade Estadual do Ceará (PPGEUECE). Professor do Instituto Superior de Teologia Aplicada (INTA).

${ }^{2}$ Professora do Programa de Pós-Graduação em Educação da Universidade Federal do Ceará (PPGE-UFC). Professora da Universidade Regional do Cariri (URCA).

${ }^{3}$ Professor da Universidade Regional do Cariri (URCA).

${ }^{4}$ Professor do Programa de Pós-Graduação em Educação da Universidade Estadual do Ceará (PPGE-UECE).

${ }^{5}$ Amaral (2010) elenca diversos conceitos sobre organismos internacionais, os quais denotam para distintas compreensões de seus objetivos, capacidade de ação e agência. Três formas se alinham melhor com a perspectiva de nossa pesquisa: "(i) organismos internacionais como instrumento político da diplomacia Estatal, ou seja, como extensão do aparelho do Estado; (ii) como arenas nas quais se formam sistemas de coordenação e negociação intergovernamental; e (iii) como agente corporativo com agenda política própria. Paralelo a esses usos, podem-se apontar também organismos internacionais como burocracias". (RITTBERGER; ZANGL apud AMARAL, 2010, p. 46).

${ }^{6}$ A elaboração deste trabalho se deu no decurso do segundo mandato de Dilma Rousseff, contudo, em função do golpe de estado perpetrado pelos setores mais conservadores, portanto, culminando no impeachment de Dilma e na ascensão de Michel Temer como presidente. Deste modo, em função do espaço temporal de sua elaboração, não modificaremos seu conteúdo.

${ }^{7}$ A reforma da educação superior nos governos petistas diz respeito ao Projeto de Lei $n^{\circ}$ 7.200/06 (acrescentado ao PL no ${ }^{\circ}$ 4.212/04 e PL n ${ }^{\circ} 4.221 / 04$ ).

${ }^{8}$ O movimento Todos Pela Educação se trata de um movimento criado em São Paulo em 2006. É constituído por empresários, presidentes de ONGs, intelectuais à serviço dos interesses do capital, entre outros.

${ }^{9}$ No que diz respeito à compreensão da particularidade capitalista brasileira recorremos às análises de Minto (2014), em que os elementos que conferem ao - não apenas - Brasil o status de país dependente diz respeito à universalização do capital em que o modo de ser (particularidade) é sempre determinado pela totalidade histórica, ainda que haja mediações no interior dessa processualidade, o desenvolvimento capitalista se dá de modo desigual e combinado, o que impulsiona nas "taxas diferenciais de lucro (superlucro)" a partir da "taxa diferencial de exploração" (MÉSZÁROS, 2008, p. 89).

${ }^{10}$ Nesse momento damos ênfase apenas nas políticas de educação superior. Sobre a crise política que assolou o exercício governamental do segundo mandato Dilma Rousseff não abordaremos em função de ultrapassar os limites do escopo deste trabalho.

${ }^{11}$ Compreendemos política focalista, a grosso modo, como uma tentativa de redirecionar recursos públicos para setores subalternos mais próximo da miséria socioeconômica por meio de instrumentos que os selecionem como beneficiários diretos; Por política compensatória, classificamos como uma ação estatal que compensa o efeito de uma intervenção à qual acarretou reações negativas. Ou seja, é uma política que atua sobre o efeito do problema e não sobre a causa concreta.

${ }^{12}$ Congresso intitulado "Ações de Responsabilidade Social em Educação: Melhores Práticas na América Latina".

13 Audiência realizada no Senado Federal em 26/05/2015. Disponível em: <https://www.youtube.com/watch?v=w81XrmZwfMY> Acesso em: 18 jan. 2016.

Recebido: março/16 Aprovado: dezembro/16 